\title{
Nie tylko Wilniana Ekslibris Erica Gilla (1882-1940) w zbiorach Biblioteki Uniwersyteckiej w Toruniu
}

\section{Wprowadzenie}

W ileńskie tradycje Uniwersytetu Mikołaja Kopernika (dalej: UMK) wpłynęły na charakter i specyfikę zbiorów gromadzonych przez Gabinet Sztuki Biblioteki Uniwersyteckiej w Toruniu. Irena Voise-Maćkiewicz, pierwszy kierownik (w latach 1951-1975) i organizator Gabinetu Sztuki, jasno określiła profil pozyskiwania zbiorów: „Biblioteka gromadzi grafikę i te ekslibrisy, które są jej aktualnie potrzebne. A więc przede wszystkim te, które są użytkowane przez macierzystą uczelnię. Stąd wynika zdecydowanie kierunkowe gromadzenie, świadome ograniczanie wymiany z przygodnymi zbieraczami"1. Gabinet Zbiorów Graficznych Biblioteki Uniwersyteckiej pełni funkcję ośrodka dokumentacyjno-badawczego dla Wydziału Sztuk Pięknych UMK, skrzętnie zbierając prace jego profesorów i wykładowców wywodzących się z wileńskiego środowiska artystycznego. Dlatego też grafika oraz ekslibris wileński i toruński stanowią najpełniejszą, najlepiej opracowaną i najszerzej prezentowaną kolekcję². Księgoznaki i grafika tworzą najbardziej wartościową, pod wzglę-

${ }^{1}$ I. Voise-Maćkiewicz, Ekslibris toruński, „Zeszyty Naukowe Uniwersytetu Mikołaja Kopernika w Toruniu, Nauki Humanistyczno-Społeczne. Nauka o Książce” 1968, z. 5 (29), s. 48.

${ }^{2}$ Zob. J. Kotłowski, Kolekcje grafiki wileńskiej okresu międzywojennego w zbiorach Biblioteki Uniwersyteckiej $w$ Toruniu [w druku]. W przygotowywanej publikacji autor zawarł pełną bibliografię swoich opracowań na temat grafiki i ekslibrisu tzw. szkoły wileńsko-toruńskiej. 
dem zabytkowym, artystycznym i poznawczym, część zasobów Gabinetu Zbiorów Graficznych.

Ekslibrisy w Bibliotece Uniwersyteckiej w Toruniu zaczęto gromadzić później niż grafikę. Zbiór ten zapoczątkowały dwie teki prac autorstwa Wojciecha Jakubowskiego zakupione w roku $1956^{3}$. Jakubowski był wówczas młodym artystą, uczniem Jerzego Hoppena, absolwentem Zakładu Grafiki Wydziału Sztuk Pięknych w Toruniu (dyplom otrzymał w 1953 r.), który z czasem stał się specjalistą w dziedzinie ekslibrisu. Wkrótce potem zaczęto systematycznie pozyskiwać również ekslibrisy zagraniczne. Obecny zbiór liczący około 40 tys. eksponatów należy do najliczniejszych w Polsce i może się poszczycić nie tylko ekslibrisami z europejskiego kręgu kulturowego, ale także z odległych egzotycznych kultur Japonii, Australii i Ameryki Południowej.

Pierwsze ekslibrisy angielskie dotarły do biblioteki z wymiany w 1961 r. Szczególny nacisk kładziono wówczas na wymianę zagraniczną4. Pośród ekslibrisów europejskich ekslibris angielski nie należy do najliczniej reprezentowanych ${ }^{5}$. W pewnym stopniu rekompensuje to fakt, że Gabinet Sztuki posiada w zbiorach pracę wybitnego brytyjskiego artysty - Erica Gilla (1882-1940).

\section{Eric Gill - artysta wszechstronny}

Eric Gill łączył w swej pracy twórczej fach kaligrafa, rysownika, rzeźEbiarza, grafika, grawera inskrypcji i typografa. To szczególny przykład romantycznej koncepcji wspólnoty sztuk wiązanych osobą twórcy, siłą jego talentu i umiejętności ${ }^{6}$. Zasłynął przede wszystkim jako twór-

3 Archiwum Biblioteki Uniwersyteckiej w Toruniu (dalej cyt. Archiwum BU Toruń), Oddział Gromadzenia - Księga Nabytków 1956, poz. K/2361. W latach 1961-1962 zakupiono od Wojciecha Jakubowskiego ok. 3000 ekslibrisów - zob. H. Baranowski, Zbiory Biblioteki Uniwersyteckiej w Toruniu, ich rozwój i kierunki przyszłego kształtowania, [w:] Studia o działalności i zbiorach Biblioteki Uniwersytetu Mikołaja Kopernika, cz. 5, Toruń 1990, s. 37.

${ }^{4}$ Archiwum BU Toruń, Oddział Gromadzenia - Księga Nabytków 1961, poz. W/61.

${ }^{5}$ Pierwsze ekslibrisy angielskie dotarły do biblioteki z wymiany w roku 1961 - Archiwum BU Toruń, Oddział Gromadzenia - Księga Nabytków 1961, poz. W/61. Szczególny nacisk kładziono wówczas na wymianę zagraniczną.

${ }^{6}$ Zob. szerzej J. Starzyński, O romantycznej syntezie sztuki. Delacroix, Chopin, Baudelaire, Warszawa 1965; M. Poprzęcka, Runge Philipp Otto, [w:] Teoretycy, artyści i krytycy o sztuce: 1700-1870, wyb., przedm. i koment. E. Grabska, M. Poprzęcka, Warszawa 1974, s. 337. 
ca ekslibrisów, liternik, projektant krojów pisma i ilustrator książek, który wniósł ogromny wkład w rozwój brytyjskiej sztuki książki. Artysta wyrósł z tradycji ruchu odrodzenia rzemiosła Arts \& Crafts ${ }^{7}$, który propagował ideę sztuki stosowanej i postulował zniesienie podziału na sztuki piękne i sztukę użytkową. Przedstawiciele ruchu Arts \& Crafts postrzegali drzeworyt jako pełną wyrazu technikę wolną od komercyjnych nacisków, służącą artyście jako nośnik indywidualnego stylu. Tajniki i możliwości techniki drzeworytniczej jako środka artystycznego wyrazu były również zgłębiane przez Edwarda Gordona Craiga (1872-1966), Edwarda Wadswortha (1889-1949), Roberta Gibbingsa (1889-1958) i wielu innych skupionych wokół licznie zakładanych towarzystw drzeworytników ${ }^{8}$. Sztuka europejska przełomu XIX i XX w. jest określana raz jako dekadentyzm, innym razem jako modernizm. Część ówczesnych artystów (należał do nich niewątpliwie Eric Gill) była zwolennikami Nowej Sztuki, poszukującymi rozwiązań nowatorskich z jednej strony, z drugiej - chętnie i świadomie nawiązującymi do sztuki epok minionych. Gill należał do tego pokolenia artystów, które przyszło na świat w momencie zasadniczego przełomu w dziejach sztuki i było świadkiem, a czasem współuczestnikiem niektórych etapów przemian - rodzenia się i przemijania wielu kolejnych kierunków i trendów od romantyzmu poprzez impresjonizm, secesję, fowizm aż do kubizmu.

Eric Gill jako artysta grafik i rzeźbiarz nie był zaliczany przez współczesnych mu teoretyków i krytyków sztuki do nurtu modernistycznego z początku XX w. ze względu na swą mediewistyczną postawę 9 . Polska współczesna badaczka różnorodnych form realizmu w sztuce lat 20. i 30. XX w. Irena Kossowska dowodzi, że Gill był w takim samym stopniu nowoczesny co średniowieczny, a jego „średniowieczność” była w dużej mierze odbiciem twórczości współczesnych mu modernistów, którzy propagowali sztukę dekoracyjną o syntetycznej formie i bogatej symbolice ${ }^{10}$. W opinii

7 I. Chilvers, Oksfordzki leksykon sztuki, Warszawa 2002, s. 46.

${ }^{8}$ Society of Wood Engravers założone przez Roberta Gibbingsa w 1920 r., English Wood-Engraving Society (1925-1931) założone przez E. G. Craiga; Color Wood Cut Society założone przez Fran Morley Flecher w 1920 r. Szerzej zob. British printmakers: 1855-1955: a century of printmaking from the etching revival to St. Ives, ed. by R. Garton, Devizes 1992, s. 84.

9 Zob. szerzej Ch. Harrison, English art and modernism 1900-1939, New Haven 1994.

${ }_{10}$ Zob. I. Kossowska, Idea dzieła sztuki sakralnej w latach dwudziestych i trzydziestych XX wieku, „Roczniki Humanistyczne. Historia Sztuki” 2000/2001, R. 48/49, z. 4, s. [251]-274; taż, Krawędź modernizmu. Neomediewistyczna rzeźba Erica Gilla, [w:] Figury i figuracje. Materiały LIV ogólnopolskiej sesji naukowej Stowarzyszenia Historyków 
Kossowskiej nadmierna prostota form oraz pozbawione ekspresji i emocji obrazowanie postaci jest dążeniem artysty do urzeczywistnienia tego, co metafizyczne i boskie w lapidarnym znaku-symbolu. Eric Gill stworzył symbolikę znaku-kształtu, którą według Kossowskiej pojmował jako „heraldyczny znak Boga"11. Cywilizacja średniowieczna zafascynowała artystę do tego stopnia, że całe życie spędził w zakładanych przez siebie wspólnotach artystyczno-religijnych. Wychwalał zalety średniowiecznych metod pracy, ubierał się jak średniowieczny rzemieślnik i sam kuł w kamieniu jak średniowieczny kamieniarz. Gill przyczynił się niewątpliwie do rozwoju techniki drzeworytniczej, a radykalizm rozwiązań formalnych wyróżniał go spośród współczesnych mu grafików. Upraszczając i geometryzując formę, podkreślał linearyzm i miękkość kształtów. Artysta nie ograniczał się jedynie do metody białej ciągłej linii i nie obawiał się również eksperymentów z użyciem ogromnych obszarów bieli w swoich grafikach.

Był także twórcą całych układów typograficznych obejmujących wszystkie zasadnicze elementy: krój pisma, kolumny druku, ornamenty i ilustracje. Projektując książki, przywiązywał taką samą wagę do liternictwa jak do wzajemnego wpływu i związku pomiędzy ryciną i towarzyszącym jej tekstem. W czasie swojego aktywnego i wypełnionego pracą twórczą życia stworzył około 12 serii krojów pisma, z których najbardziej znane są: Perpetua (1925-1930), Gill Sans Serif (1927), Joanna (1930) i Bunyan (1934) ${ }^{12}$. Eric Gill wykonał ilustracje i dekoracje do 138 książek, z czego 15 dla Golden Cockerel Press. Były to dzieła literackie i religijne o światowym znaczeniu, takie jak: Troilus and Criseyde (Waltham St. Lawrence: Golden Cockerel Press, 1927), Canterbury Tales (Waltham St. Lawrence: Golden Cockerel Press, 1929-1931) i The Four Gospel (Waltham St. Lawrence: Golden Cockerel Press, 1931), Canticum Canticorum (Weimar: Cranach Press, 1931), The Passion of Our Lord (London: Faber \& Faber, 1934) i The Bible w wydaniu Aldine Press (London 1934). Tworząc ilustracje i zdobienia drzeworytnicze do tych wydań, posługiwał się licznymi formułami stylistycznymi, przyczyniając się w ten sposób do rozwoju tej techniki jako środka wyrazu artystycznego.

Sztuki, Lublin 20-22 października 2005, pod red. M. Kitowskiej-Łysiak, Warszawa 2006, s. 153-[177].

${ }^{11}$ I. Kossowska, Idea dzieła sztuki sakralnej..., s. 253-254.

12 Bunyan zaprojektowany w 1934 r., a przystosowany do składu maszynowego i nazwany Pilgrim w 1953 r. Zob. Eric Gill [on-line]. W: Wikipedia. The Free Encyclopedia [dostęp 10 sierpnia 2010]. Dostępny w World Wide Web: http://en.wikipedia.org/wiki/Eric_Gill. 
Na oblicze sztuki Erica Gilla wpływ wywarł również fakt, że był on katolikiem, czczącym poprzez sztukę Jezusa i Marię. Nie przeszkadzało mu to jednocześnie czcić seksualności, wręcz przeciwnie - często łączył te dwa tematy w jednym dziele (drzeworyt Boscy kochankowie z roku 1922). Artysta interesował się także kulturą i sztuką hinduską, której ikonografia religijna jest przepełniona wątkami erotycznymi ${ }^{13}$.

Ekscentryczny styl życia i niezwykle płodna twórczość Erica Gilla pozostają w kręgu zainteresowań nie tylko badaczy teoretyków, lecz także artystów i projektantów. Polscy plakaciści i typografowie z lat 20. i 30. XX w. czerpali również ze wzorów czcionek Gilla, należeli do nich m.in. Stefan Norblin i Franciszek Seifert ${ }^{14}$. Amerykański grafik multimedialny John F. Sherman stworzył czcionkę Felicitas, zainspirowany projektem Gilla dla czcionki Perpetua, wprowadzonej przez Monotype Foundry w 1929 r. Wzory czcionek Gill Sans i Perpetua są wciąż bardzo popularne, np. obecna czcionka logo BBC.

Według Erica Gilla, który był także autorem pism z teorii sztuki, religii i filozofii społecznej, współczesne mu pokolenie (reprezentujące cywilizację opartą na doktrynie wolnej woli) było generacją artystów, ponieważ to praca, która jest spełnieniem wolnej woli, czyni każdego człowieka twórcą ${ }^{15}$. W rozumieniu Gilla artysta to rzetelny rzemieślnik wierny wobec materiału, z drugiej zaś strony łączy się z Bogiem w akcie twórczym, który jest dla niego mistycznym przeżyciem. To właśnie z tego czerpał siły do tworzenia ${ }^{16}$.

Liczne kolekcje obejmujące różne gatunki twórczości artystycznej oraz spuściznę intelektualną artysty są zgromadzone w Wielkiej Brytanii i Stanach Zjednoczonych ${ }^{17}$. Muzeum Wiktorii i Alberta w Londynie (ang. Victoria \& Albert Museum) dysponuje najpełniejszą kolekcją dzieł artysty przekazaną w 1952 r. do Działu Grafiki i Rysunków (ang. Department of Prints and Drawings) przez jego żonę Mary Ethel Gill.

${ }^{3}$ I. Kossowska, Krawędź modernizmu..., s. 165.

${ }^{14}$ W. Serwatowski, Plakat Art-Deco ze zbiorów Muzeum we Lwowie [on-line]. Kultura polska: Portal kultury polskiej: www.culture.pl [dostęp 10 sierpnia 2010]. Dostępny w World Wide Web: http://www.culture.pl/pl/culture/artykuly/wy_in_wy_plakat_art_ deco_lwow.

${ }^{15}$ E. Gill, Idiocy or ill will, [w:] Essays by Eric Gill, published in one volume by Jonathan Cape, London 1940, s. [42].

${ }^{16}$ I. Kossowska, Idea dzieła sztuki sakralnej..., s. 252.

${ }^{17}$ Kolekcje obejmujące spuściznę intelektualną i artystyczną Erica Gilla znajdują się w: Vitoria \& Albert Museum - London, Tate Gallery - London, Special Collection of University of Notre Dame - Indiana USA. 


\section{Eric Gill - twórca ekslibrisów}

Eric Gill był niekwestionowanym mistrzem ekslibrisu drzeworytni-

- czego. W kluczowych opracowaniach dotyczących drzeworytu brytyjskiego jest uwzględniany częściej niż inni graficy ${ }^{18}$. W opinii historyka i znawcy ekslibrisów Briana N. Lee to właśnie Gill stworzył nowoczesny drzeworytniczy ekslibris, a Reynold Stone (1909-1979) był jego godnym następcą. Spośród 53 ekslibrisów przypisywanych Ericowi Gillowi tylko cztery zostały wykonane techniką miedziorytu. Artysta tworzył księgoznaki na zamówienie osób prywatnych i instytucji. Każda odbitka miała zastrzeżenie „not for sale” (nie na sprzedaż). Obecnie ekslibrisy Gilla wchodzą w skład kolekcji obejmujących jego spuściznę intelektualną i artystyczną i są przechowywane w Los Angeles (The William Andrews Clark Memorial Library, University of California), San Francisco (The Richard Gleeson Library at the University of San Francisco) i Londynie (Victoria \& Albert Museum, Tate Gallery). Na podstawie tych zbiorów Christopher Skelton opracował katalog ekslibrisów Gilla ${ }^{19}$.

Ekslibrisy Erica Gilla przedstawiają niezwykle kompletny wykładnik rozwoju artystycznego i doświadczeń warsztatowych twórcy, pomimo że stanowią nieznaczną liczebnie część jego twórczości graficznej ${ }^{20}$, a nawet mniejszy fragment jego oeuvre. Istnieje pewnego rodzaju zależność między zasobem używanych środków formalnych a repertuarem motywów ikonograficznych stosowanych przez Gilla w ekslibrisach. W przedstawieniach religijnych widoczne jest czytelne nawiązanie do archaicznych i ascetycznych form sztuki bizantyńskiej i romańskiej. Natomiast posługując się tematyką świecką inspirowaną naturą, artysta zaadaptował subtelny linearno-dekoracyjny styl secesji. Liczną grupę stanowią ekslibrisy typograficzne, mające najczęściej formę literniczą, ozdobione prostą ramką. Kształt pisma tych kompozycji jest oryginalny i świadczy o odrębnym stylu artysty, na który składają się prostota, czytelność i czystość wykonania z jednej strony, a wyrazistość i klasyczna, estetyczna forma z drugiej. Istnieje również zbiór ekslibrisów o typowo wschodniej stylistyce z wi-

${ }^{18}$ Zob. następujące publikacje: S. Brett, Out of the wood. British woodcuts \& wood engravings 1890-1945, London 1991; British printmakers: 1855-1955...

19 The engraved bookplates of Eric Gill, 1908-1940, com. by Ch. Skelton, Pinner 1986.

${ }^{20}$ Katalog kolekcji Victoria \& Albert Museum odnotowuje 1000 grafik Gilla, zob. The engraved work of Eric Gill, Victoria \& Albert Museum, com. by J. Physick, London 1963. Katalog ten towarzyszył retrospektywnej wystawie grafik Erica Gilla zorganizowanej przez Victoria \& Albert Museum. 
zerunkami stylizowanych stworów: gryfów, smoków czy lwów. Zarówno rozpiętość motywów ikonograficznych, jak i różnorodność rozwiązań formalno-stylistycznych świadczą o przywiązaniu artysty do kanonów sztuki chrześcijańskiej, a jednocześnie o jego zainteresowaniu współczesnymi mu trendami artystycznymi.

\section{Ekslibris Miriam Rothschild}

W Muzeum Wiktorii i Alberta w Londynie znajdują się dwie odbitki drzeworytnicze (w tym jedna próbna) ekslibrisu Miriam Rothschild, wykonane przez artystę w $1932 \mathrm{r}^{21}$

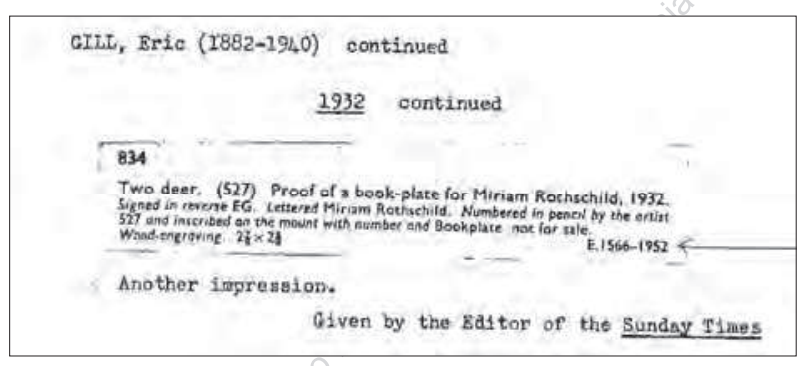

Opis katalogowy ekslibrisu dla Miriam Rothschild autorstwa Erica Gilla, 1932, Department of Prints and Drawings Victoria \& Albert Museum

Źródło: C. Flood, Fwd: Eric Gill [on-line]. Do: A. Klugowska. 28 listopada 2006, 10.25 [dostęp 10 sierpnia 2010]. Korespondencja osobista.

W Zbiorach Graficznych Biblioteki Uniwersyteckiej w Toruniu znajduje się kopia, reprodukcja fotochemigraficzna omawianego ekslibrisu. Eric Gill określany w literaturze fachowej jako najwybitniejszy brytyjski artysta-rzemieślnik znaczną część swoich prac wykonywał na zamówienia. Tak było również w przypadku Miriam Rothschild (1908-2005) ${ }^{22}$, pochodzącej ze słynnej brytyjskiej rodziny bankierów, która jako wybitny zoolog amator

${ }^{21}$ Tłumaczenie opisu katalogowego: „Dwie sarny. Próbna odbitka ekslibrisu dla Miriam Rothschild, 1932. Sygnowana na rewersie EG. Opatrzona inskrypcją Miriam Rothschild. Oznaczona numerem 527 napisanym przez artystę ołówkiem na ramce numer i napis: Ekslibris nie na sprzedaż. Drzeworyt. Kolejna odbitka ofiarowana przez redaktora «The Sunday Times»".

${ }^{22}$ Miriam Rothschild [on-line]. W: Wikipedia. Wolna Encyklopedia [dostęp 10 sierpnia 2010]. Dostępny w World Wide Web: http://pl.wikipedia.org/wiki/Miriam_Rothschild. 
i oddany obrońca zwierząt zleciła mu wykonanie ekslibrisu dla swojej prywatnej biblioteki, zastrzegając sobie prawo własności znaku. Z tego powodu jest rzeczą raczej niemożliwą, aby do zbiorów Biblioteki Uniwersyteckiej trafiła oryginalna odbitka tego ekslibrisu (zob. fot.). Jednocześnie kwerenda przeprowadzona w zbiorach specjalnych największych, naukowych bibliotek polskich - Bibliotece Narodowej w Warszawie, Bibliotece Uniwersytetu Jagiellońskiego w Krakowie, Ossolineum we Wrocławiu, Bibliotece Książąt Czartoryskich w Krakowie, Bibliotece PAN w Gdańsku, Bibliotece PAN w Kórniku oraz bibliotekach uniwersyteckich w Poznaniu, Warszawie i Wrocławiu - wykazała, że nie mają one w swych zasobach prac autorstwa Erica Gilla. Tym większego znaczenia nabiera egzemplarz toruński.

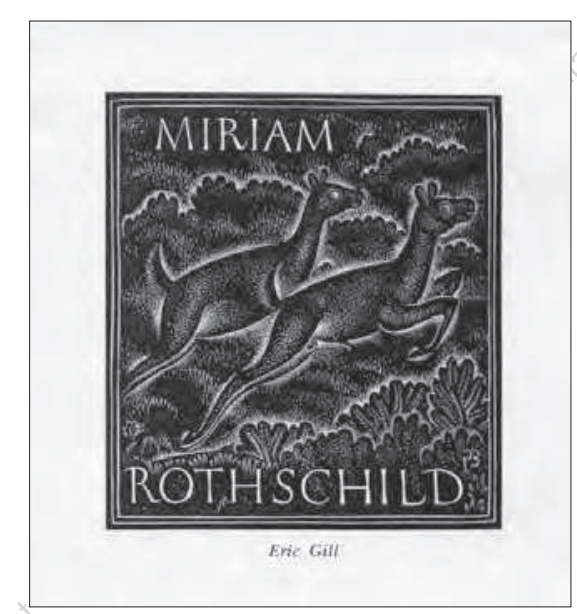

Fotografia. Ekslibris Miriam Rothschild, autor: Eric Gill, drzeworyt 1932 r.

(fot. autorka)

Źródło: Gabinet Zbiorów Graficznych Biblioteki Uniwersyteckiej w Toruniu, sygn. G. 10569.

Przegląd i analiza literatury omawiającej twórczość Erica Gilla wykazały, że ekslibris drzeworytowy Miriam Rothschild jest bardzo rzadko publikowany $^{23}$. Ukazuje on parę młodych saren - osobników obojga płci

${ }^{23}$ The Engraved Work of Eric Gill, Victoria \& Albert Museum, London 1963 - katalog prac Gilla przekazanych do muzeum przez żonę artysty. Nie prezentuje on jednak ekslibrisu Miriam Rothschild, pomimo że kolekcja artysty znajdująca się w Victoria \& Albert Museum obejmuje dwie odbitki tego ekslibrisu, sygnowanego przez artystę $\mathrm{z}$ adnotacją na ramce „nie na sprzedaż” (not for sale). Omawiany ekslibris jest publikowany w: The engraved bookplates of Eric Gill..., s. 60. 
- w galopie wśród krzewów. Artysta posłużył się symbolicznym, a zarazem heraldycznym wizerunkiem zwierzyny płowej, który może sugerować słowa Psalmu 42 z Pieśni nad Pieśniami: ,jak łania pragnie wody ze strumieni, tak dusza moja pragnie Ciebie Boże"24. Całość przedstawienia ujęta jest w ramy z kompozycji literniczej „MIRIAM ROTHSCHILD”. Ekslibris jest sygnowany typowym dla artysty monogramem „EG” w prawym dolnym rogu i dodatkowo na ramce podpisany „Eric Gill” czcionką Arial jego autorstwa. Kompozycja ekslibrisu jest oparta na dominującej czarną tonacją płaszczyźnie. Przedstawienia sylwetek zwierząt i motywów roślinnych są modelowane rozświetlonymi delikatnie punktami i plastyczną białą linią konturów. Stosując, tak charakterystyczną dla kierunków postimpresjonistycznych, metodę rozproszonych, skrzących się bielą punkcików, artysta po mistrzowsku operuje światłocieniem, wydobywając za jego pomocą trójwymiarowość form. Pełnoplastyczna kompozycja ekslibrisu ujawnia czytelne podobieństwo formalne do stylu reliefów o różnym natężeniu światła. Tego typu środki wyrazu artystycznego są charakterystyczne dla drzeworytów Erica Gilla z przełomu lat 20. i 30. XX w. Mając świadomość pokrewieństwa tych dwóch technik, artysta bardzo często ten sam motyw realizował zarówno w rzeźbie, jak i w drzeworycie ${ }^{25}$.

Motyw zwierząt żyjących na wolności, których zagorzałą orędowniczką była Miriam Rothschild, artysta wybrał ze względu na zainteresowania i charakter księgozbioru właścicielki znaku. Ekslibris ten może być wyrazem postawy artysty wobec natury, która jako doskonałe dzieło stworzenia jest najlepszym wzorem i źródłem tworzenia. Dzięki obserwacji zmienności natury artysta mógł wybrać najbardziej odpowiedni materiał (w tym przypadku klocek drzeworytniczy) i motyw dekoracyjny. W przedstawieniu dwóch młodych saren Gill w sposób bezpośredni nawiązuje do natury, nie jest to jednak bierne jej naśladowanie czy kopiowanie, ale dążenie do uproszczeń i dekoracyjności formy, tak typowej dla sztuki art déco.

Zarówno autora ekslibrisu, jak i jego właścicielkę (rzeczniczkę ochrony środowiska) cechowała podobna postawa wobec natury, pełna szacunku i świadoma potrzeby życia z nią w zgodzie i harmonii.

${ }^{24}$ Księga Psalmów 42.2, [w:] Pismo Święte Starego i Nowego Testamentu, Poznań 2003.

${ }^{25}$ Zob. ilustracje i analizę porównawczą motywów Madonny z Dzieciątkiem, Ukrzyżowania i obejmujących się kochanków w: I. Kossowska, Krawędź modernizmu..., s. 153-[177]; zob. także przykłady przytaczane w: M. Yorke, Eric Gill. The man of flesh and spirit, London 2000, s. 181. 


\section{Not only Vilniana. Bookplate by Eric Gill (1882-1940) in the University Library Collection in Toruń Abstract}

Documents and items of special collections of Polish academic libraries constitute the treasure of our national heritage as well as European and world cultural legacy. The issues such as acquisition profile of University Library Art Collection in Torun, the origin and distinctive character of bookplates collection were presented in the article. The analysis of archival materials of the University Library in Torun allowed to determine provenance of English bookplates collection. The remarkable, outstanding British artist Eric Gill (1882-1940) and his artistic attitude was portrayed. He was the author of the Miriam Rothschild bookplate (1932) which is currently held in Art Collection of University Library in Torun as well as Victoria \& Albert Museum in London. A preliminary search of library and museum holdings in Poland, USA and Great Britain showed that only The Art Collection of University Library in Torun and Victoria \& Albert Museum in London possess the Miriam Rothschild bookplate of Eric Gill in their holdings. The literature research covering Gill's oeuvre showed that the bookplate in question is very occasionally presented and it has never been discussed. For that reason the attempt has been made to characterize modes of artistic expression and stylistic onces of the bookplate as well as Gill's attitude to nature. 